\title{
Final Technical Report for
}

\author{
AA FEST \\ General Circulation Model Development: \\ Past, Present and Future. \\ A Symposium in Honor of Professor Akio Arakawa
}

Grant Number: DE-FG03-97ER62455

Kayo Ide (internet: kayo@atmos.ucla.edu; office: 310-825-2970)

Roger M. Wakimoto (internet: roger@atmos.ucla.edu; office: 310-825-1751)

University of California, Los Angeles

\section{SUMmaRY}

On January 20-22, 1998, "AA Fest. A Symposium on General Circulation Model Development: Past, Present, and Future" was held at the NorthWest Campus Auditorium of University of California, Los Angeles, in honor of Professor Akio Arawaka. The Symposium consisted of two-and-a-half-day technical presentations, along with a banquet in the opening evening and a reception during the poster session of the second evening.

AA Fest was attended by over 100 scientific participants. A list of participant is provided in Appendix, a summary article accepted for publication in BAMS (Randall et al., 1999). It was a great privilege for the organizers to have the participation of many leading Japanese scientists, as well as the participants from the U.S. and other nations.

The technical presentations were arranged in the three main sessions entitled "The First 37 Years," "Current Research," and "Future Directions" (Appendix). Each session included both invited and contributed papers. The invited papers were presented orally; some of the contributed papers were presented orally, while others were presented in the form of posters. The list of papers presented at the $A A$ Fest is included in Appendix.

Professor Akio Arakawa presented two honorary lectures, one at the opening and the 


\section{DISCLAIMER}

This report was prepared as an account of work sponsored by an agency of the United States Government. Neither the United States Government nor any agency thereof, nor any of their employees, make any warranty, express or implied, or assumes any legal liability or responsibility for the accuracy, completeness, or usefulness of any information, apparatus, product, or process disclosed, or represents that its use would not infringe privately owned rights. Reference herein to any specific commercial product, process, or service by trade name, trademark, manufacturer, or otherwise does not necessarily constitute or imply its endorsement, recommendation, or favoring by the United States Government or any agency thereof. The views and opinions of authors expressed herein do not necessarily state or reflect those of the United States Government or any agency thereof. 


\section{DISCLAIMER}

Portions of this document may be illegible in electronic image products. Images are produced from the best available original document. 
other as the conclusion of the Symposium. The two lectures were filmed professionally by the UCLA's Audio Video Services. Copies of the VHS have been archived at the Archives and Records Management Program of National Center for Atmospheric Research and several international meteorological research institutes for public records. A copy was provided to Department of Energy. In due course, a book based on the papers presented at the AA Fest is being edited by David A. Randall which will be provided to Department of Energy when published.

The AA Fest was organized efficiently via internet, especially by the means of the WWW: http://www.atmos.ucla.edu/AA_fest, including program, abstracts, registration and local information. Currently the WWW site hosts a photo gallery from the Symposium.

\section{PUblication AND AUdio Video}

Arakawa, A., 1998: A video of the two lectures, "A Perspective on the early years of general circulation modeling" and "Future Development of General Circulation Models,", AA Fest: A Symposium on General Circulation Model Development." January 1998, Los Angeles. Public archive at National Center for Atmospheric Research, Archives and Records Management Program (information available via WWW at http://www.dir.ucar.edu/iss/lib/archive/homepage.html).

- the VHR has been provided to Department of Energy.

Randall, D. A. (Ed.), 1999: General Circulation Model Development: Past, Present and Future, Academic Press, in preparation.

- to be provided to Department of Energy at the time of publication.

Randall, D. A., K. Ide and R. M. Wakimoto, 1999: Summary of general Circulation Modeling: Past, Present, and Future, A Symposium in Honor of Akio Arakawa. Bulletin of the American Meteorological Society, accepted.

- Appendix. 


\title{
Summary of
}

\section{General Circulation Modeling: Past, Present, and Future}

\author{
A Eumoosum in tonor of Akio Arakawa
}

David A. Randall ${ }^{1}$, Kayo Ide $^{2}$, and Roger Wakimoto ${ }^{2}$

Accepted

In preparation for the

Bulletin of the American Meteorological Society

1. Department of Atmospheric Science Colorado State University

Fort Collins, Colorado

2. Department of Atmospheric Sciences UCLA

Los Angeles, California 
On January 20-22, 1998 a Symposium was held at the Northwest Campus Auditorium on the UCLA ${ }^{3}$ campus. The title of the Symposium was "General circulation modeling, past present and future: A symposium in honor of Akio Arakawa." The Symposium, which was informally called the "AA Fest," was organized as a celebration of the career of UCLA's Prof. Akio Arakawa, (Fig. 1) who has been among the leaders in the field of atmospheric general circulation model (GCM) development, from its very beginning. The purpose of this brief report is to summarize the Symposium for the benefit of the community at large.

Akio Arakawa obtained his B. Sc. in Physics from Tokyo University, 1950, and his D. Sc. in Meteorology from the same institution in 1961. In the early 1950s, he served for one year on a weather ship in the North Pacific, an experience which made a strong impression on him. Subsequently, still during the 1950s, he conducted forecasting research at the Meteorological Research Institute which is operated by the Japan Meteorological Agency. The first numerical simulation of the general circulation by Phillips (1956) inspired him, and during 1961-1963 he came to UCLA as an Assistant Research Meteorologist, working with Prof. Yale Mintz on the development of what was to become the Mintz-Arakawa GCM (Johnson and Arakawa, 1996). After returning to Japan for two years, he joined the faculty at UCLA in 1965, and has remained there ever since, conducting his wide-ranging research on GCM development and related scientific issues.

Among the most remarkable qualities of his work has been his ability to make major contributions both to the development of new numerical methods, as exemplified by his 1966 paper on the Arakawa Jacobian, and to the development of new physical parameterizations, as exemplified by his 1974 paper with Wayne Schubert on what has become known as the ArakawaSchubert cumulus parameterization. The fields of numerical analysis on the one hand and physical

3. University of California at Los Angeles. 


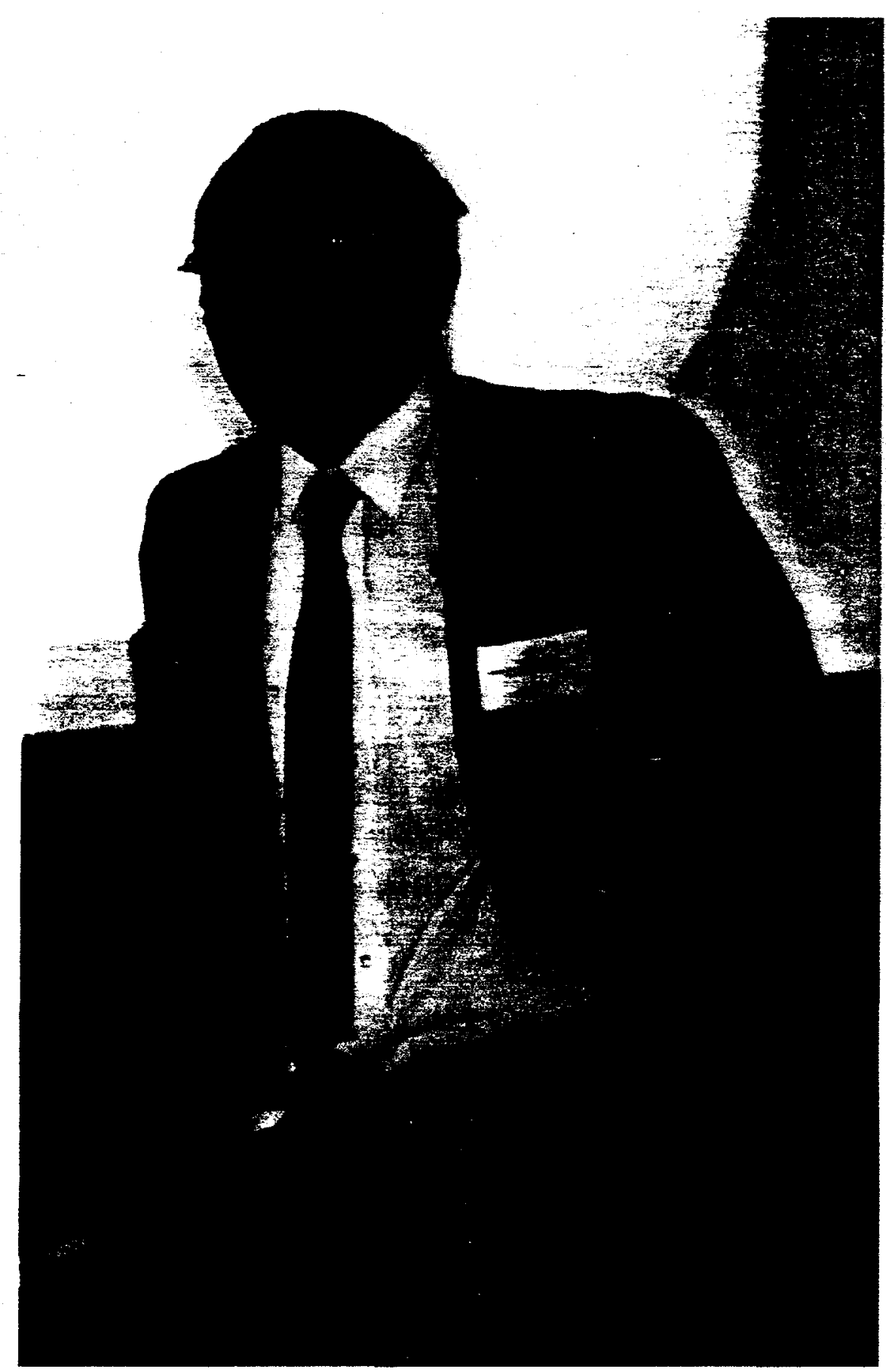

Figure 1: A photograph of Akio Arakawa taken during one of his lectures at the AA Fest. 
parameterization on the other are so different from each other that it is difficult to believe that one person could excel at both. Akio Arakawa's work has shown not only that the gap between these two disciplines can be bridged with great success, but that it must be bridged in order to create a coherent modeling framework. In particular, his work demonstrates that numerical methods can and should be designed from a highly physical perspective which goes far beyond the usual considerations of order of accuracy and linear stability.

Besides his strong research contributions, Prof. Arakawa has been very successful as a teacher, inspiring several generations of graduate students and young post-doctoral colleagues with his enthusiasm and vision.

The AA Fest was organized by a Program Committee, whose members are listed in Table 1. Participants came from the U.S., Japan, Europe, Mexico, South Korea, and Australia. A list of

Table 1: The members of the Program Committee.

\begin{tabular}{|l|}
\hline Anthony Hollingsworth \\
European Centre for Medium-Range Forecasts, UK \\
\hline Masahide Kimoto \\
Center for Climate System Research, \\
University of Tokyo, Japan \\
\hline Carlos Roberto Mechoso \\
Department of Atmospheric Sciences, \\
University of California, Los Angeles, USA \\
\hline David Randall \\
Department of Atmospheric Science, \\
Colorado State University, USA \\
\hline Akimasa Sumi \\
Center for Climate System Research, \\
University of Tokyo, Japan \\
\hline Roger Wakimoto, Chair of the Program Committee \\
Department of Atmospheric Sciences, \\
University of California, Los Angeles, USA \\
\hline Michio Yanai \\
Department of Atmospheric Sciences, \\
University of California, Los Angeles, USA \\
\hline
\end{tabular}


participants is given in Table 2. A group photo of the participants is shown in Fig. 2. The

Table 2: A list of the participants.

\begin{tabular}{|c|c|}
\hline Name & Affiliation \\
\hline Akio Arakawa & UCLA \\
\hline Brian Bosart & UCLA \\
\hline Huaqing Cai & UCLA \\
\hline June Chang & UCLA \\
\hline Winston Chao & NASA Goddard Space Flight Center \\
\hline Baode Chen & UCLA \\
\hline Jeng-Ming Chen & FNMOC, Naval Research Laboratory \\
\hline Chia Chou & UCLA \\
\hline Anindita Datta & UCLA \\
\hline Anthony Drummond & UCLA \\
\hline Paul N. Edwards & Stanford University \\
\hline Annmarie Eldering & UCLA \\
\hline Kerry Emanuel & Massachusetts Institute of Technology \\
\hline John Farrara & UCLA \\
\hline Rick Fort & UCLA \\
\hline Robert Fovell & UCLA \\
\hline Blanca Gallego & UCLA \\
\hline Sylvia George & UCLA \\
\hline Michael Ghil & UCLA \\
\hline Milt Halem & NASA Goddard Space Flight Center \\
\hline David Halpern & UCLA \\
\hline Robert L. Haney & Naval Postgraduate School \\
\hline James Hansen & Goddard Institute for Space Studies \\
\hline Anthony Hollingsworth & European Centre for Medium Range Weather Forecasts \\
\hline Chih-Wen Hung & UCLA \\
\hline Kayo Ide & UCLA \\
\hline Toshiki Iwasaki & Japan Meteorological Agency, Tokyo \\
\hline
\end{tabular}




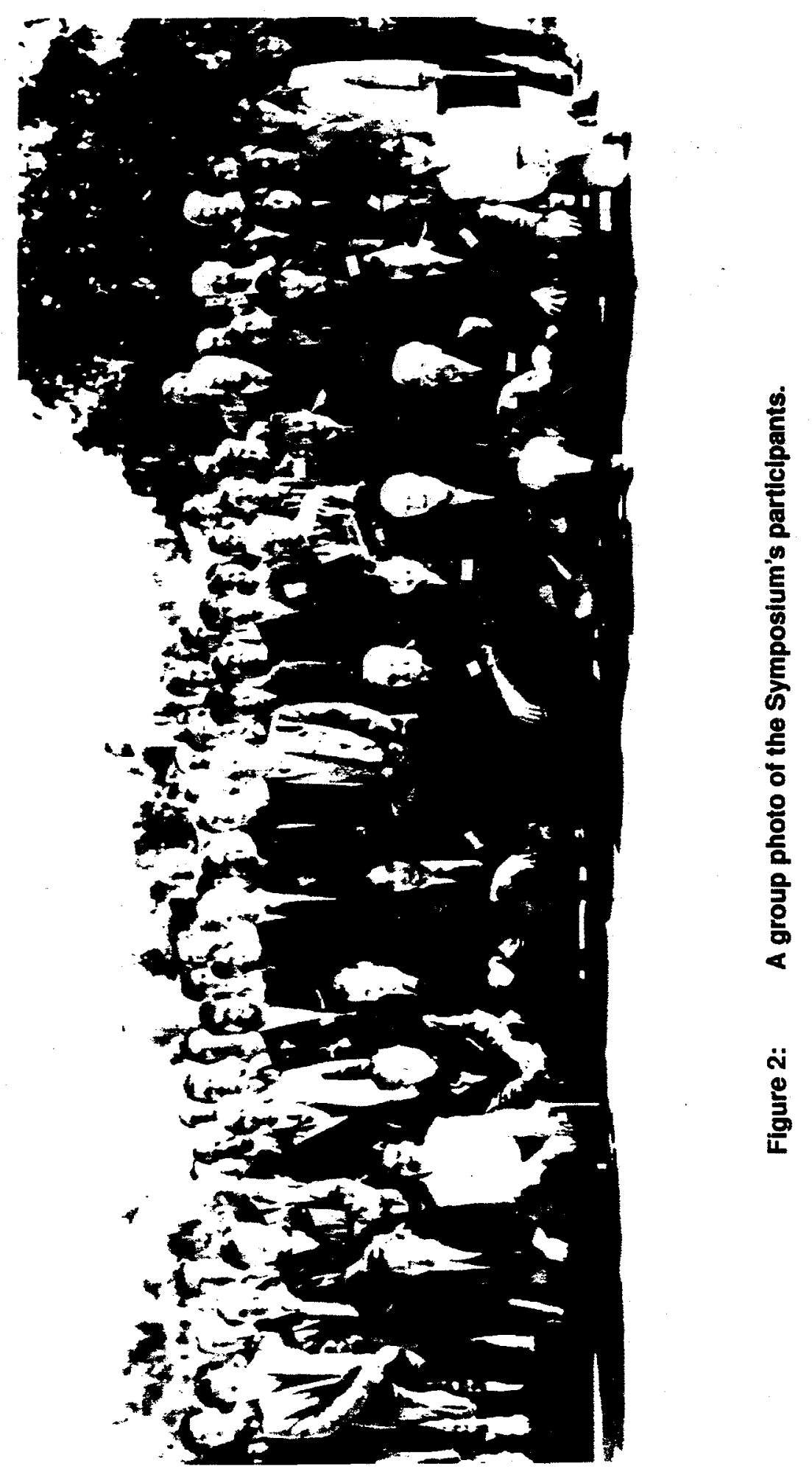


Table 2: A list of the participants.

\begin{tabular}{|c|c|}
\hline Name & Affiliation \\
\hline Donald Johnson & University of Wisconsin \\
\hline Joon-Hee Jung & UCLA \\
\hline Sajal K. Kar & Bureau of Meteorology Research Center, Melbourne, Australia \\
\hline Mehmet Karaca & UCLA \\
\hline Akira Kasahara & National Center for Atmospheric Research \\
\hline Jeong-Woo Kim & Yonsei University, Seoul, South Korea \\
\hline Young-Joon Kim & UCLA/Jet Propulsion Laboratory \\
\hline Masa Kimoto & Center for Climate System Research \\
\hline Akio Kitoh & Meteorological Research Institute, Tsukuba, Japan \\
\hline Martin Koehler & UCLA \\
\hline Celal Sukru Konor & UCLA \\
\hline Seongjoon Koo & UCLA \\
\hline Steve Krueger & University of Utah \\
\hline Daniel M. Landau & UCLA \\
\hline Jeffrey Lew & UCLA \\
\hline John Lewis & National Severe Storms Laboratory \\
\hline Jui-Lin Frank Li & UCLA \\
\hline Chichung Lin & UCLA \\
\hline Johnny Lin & UCLA \\
\hline Kuo Nan Liou & UCLA \\
\hline Chi-Sann Liou & Naval Research Laboratory \\
\hline Karen Yuezhen Liu & Jet Propulsion Laboratory \\
\hline Stephen Lord & National Centers for Environmental Prediction \\
\hline Francois M. Lott & UCLA \\
\hline Larry Lyons & UCLA \\
\hline Hsiang Sean Lu & UCLA \\
\hline Rong Lu & UCLA \\
\hline Chung-Chun Ma & UCLA \\
\hline
\end{tabular}


Table 2: A list of the participants.

\begin{tabular}{|c|c|}
\hline Name & Affiliation \\
\hline Syukuro Manabe & Frontier Program \\
\hline Steve L. Marcus & Jet Propulsion Laboratory \\
\hline Taroh Matsuno & Hokkaido University \\
\hline C. Roberto Mechoso & UCLA \\
\hline Fedor Mesinger & National Centers for Environmental Prediction \\
\hline Kikuro Miyakoda & George Mason University \\
\hline Chin-Hoh Moeng & National Center for Atmospheric Research \\
\hline Shrinivas Moorthi & National Centers for Environmental Prediction \\
\hline David Neelin & UCLA \\
\hline Atusi Numaguti & Center for Climate System Research \\
\hline Suzanne Paulson & JCLA \\
\hline Arturo Quintanar & National Autonomous University of Mexico \\
\hline David Randall & Colorado State University \\
\hline Andy Robertson & UCLA \\
\hline John Kevin Roskovensky & UCLA \\
\hline Scott Sandgathe & Office of Naval Research \\
\hline Wayne Schubert & Colorado State University \\
\hline Albert J. Semtner & Naval Postgraduate School \\
\hline Richard Somerville & University of California at San Diego \\
\hline Joe Spahr & UCLA \\
\hline Pamela Stephens & National Science Foundation \\
\hline Max Suarez & NASA Goddard Space Flight Center \\
\hline Akimasa Sumi & Center for Climate System Research \\
\hline $\mathrm{H} \sin -\mathrm{H} \sin \mathrm{Syu}$ & UCLA \\
\hline Remi Tailleux & UCLA \\
\hline Rafael Terra & UCLA \\
\hline Richard Thorne & UCLA \\
\hline Yudong Tian & UCLA \\
\hline
\end{tabular}


Table 2: A llst of the participants.

\begin{tabular}{|c||c|}
\hline Name & Affliation \\
\hline \hline Tatsushi Tokioka & Meteorological Research Institute, Tsukuba, Japan \\
\hline Wen-wen Tung & UCLA \\
\hline Richard Turco & UCLA \\
\hline Roger Wakimoto & UCLA \\
\hline Chih-Ping Wang & UCLA \\
\hline Morton Wurtele & UCLA \\
\hline Xiaoqing Wu & National Center for Atmospheric Research \\
\hline Kuan-Man Xu & Colorado State University \\
\hline Michio Yanai & UCLA \\
\hline Jin-Yi Yu & UCLA \\
\hline Ning Zeng & UCLA \\
\hline
\end{tabular}

organizers were particularly happy to have the participation of many leading Japanese scientists, as well as participants from the U.S. and the other nations listed in Table 2.

The AA Fest was arranged in three sections entitled "The First 37 Years," "Current Research," and "Future Directions," respectively. Akio Arakawa presented the opening and closing papers of the Symposium. Each session included both Invited Papers and Contributed Papers. Some of the Contributed Papers were presented orally, while others were given in the form of posters. A list of the papers is given in Table 3 .

Table 3: A list of the papers presented at the AA Fest. A "*" indicates an invited paper.

\begin{tabular}{|c||l|}
\hline \multicolumn{2}{|c|}{ Session 1: The First 37 years } \\
\hline Akio Arakawa* & $\begin{array}{l}\text { A Personal Perspective on the Early Years of General Circulation Modeling at } \\
\text { UCLA }\end{array}$ \\
\hline Fedor Mesinger * & Numerical Methods \\
\hline Wayne Schubert* & A Retrospective View of Arakawa's Ideas on Cumulus Parameterization \\
\hline Akira Kasahara & On the Origin of Cumulus Parameterization for Numerical Prediction Models \\
\hline James Hansen * & Climate Simulation \\
\hline
\end{tabular}


Table 3: A llst of the papers presented at the AA Fest. A "*" Indicates an invited paper.

\begin{tabular}{|c|c|}
\hline Tatsushi Tokioka * & $\begin{array}{l}\text { Climate Services at the Japan Meteorological Agency and General Circulation } \\
\text { Models }\end{array}$ \\
\hline $\begin{array}{l}\text { K. Miyakoda, A. } \\
\text { Navarra, and M.N. } \\
\text { War* }\end{array}$ & ENSO-Asian-Monsoon Oscillation System \\
\hline John Lewis & Clarifying the Dynamics of the General Circulation: Phillips' 1956 Experiment \\
\hline Robert Haney & $\begin{array}{l}\text { The General Circulation of the California Current: Observations and } \\
\text { Simulations }\end{array}$ \\
\hline $\begin{array}{c}\text { Milton Halem, } \\
\text { J.Kuoatchou and A. } \\
\text { Hudson }\end{array}$ & $\begin{array}{l}\text { A Retrospective Analysis of the Chamey et al., } 1969 \text { Numerical Experiments } \\
\text { With the Mintz-Arakawa General Circulation Model }\end{array}$ \\
\hline Masahide Kimoto & The North Pacific Decadal Oscillation Simulated by the CCSR Coupled GCM \\
\hline & Session 2: Current Research \\
\hline Taroh Matsuno* & $\begin{array}{l}\text { A New Form of the Dynamics Equation of Visco-Elastic Media Suited to } \\
\text { Numerical Integration }\end{array}$ \\
\hline $\begin{array}{l}\text { Anthony } \\
\text { Hollingsworth* }\end{array}$ & $\begin{array}{l}\text { Research and Development for Medium and Extended-range Forecasts: } \\
\text { Methods, Results and Prospects }\end{array}$ \\
\hline Kerry Emanuel* & Quasi-Equilibrium Thinking \\
\hline Akio Kitoh & $\begin{array}{l}\text { SST Variability and Its Mechanism in the MRI Coupled Atmosphere-Ocean } \\
\text { GCM and the Coupled Atmosphere-Mixed-Layer Ocean Model }\end{array}$ \\
\hline Paul N. Edwards & A GCM Family Tree: The Major Models and Their Descendants \\
\hline Martin Kohler & On the Decay of Ice Clouds and Its Representation in AGCMs \\
\hline Richard Somerville & Cloud-Radiation Feedbacks in Climate: Models vs. Observations \\
\hline \multicolumn{2}{|r|}{ Papers presented in the Poster Session } \\
\hline Winston Chao & The Origin of Monsoon Onset \\
\hline Anthony Drummond & General Circulation Models and High Performance Computing \\
\hline John Farrara & $\begin{array}{l}\text { Predictions of anomalous winter extratropical circulations associated with the } \\
\text { 1997-98 ENSO event using the UCLA AGCM }\end{array}$ \\
\hline Toshiki Iwasaki & $\begin{array}{l}\text { A Possible Link of Aerosols to Asian Summer Monsoon and Its Implication in } \\
\text { Long-Range Numerical Weather Prediction }\end{array}$ \\
\hline Sajal Kar & $\begin{array}{l}\text { A Semi-Implicit Semi-Lagrangian Formulation of the BMRC Regional } \\
\text { Forecast Model }\end{array}$ \\
\hline Jeong-Woo Kim & Monsoon and Desert Climates in Asia \\
\hline Young-Joon Kim & $\begin{array}{l}\text { Parameterization of the Effects of Orography in the UCLA AGCM; Past, } \\
\text { Present and Future }\end{array}$ \\
\hline
\end{tabular}


Table 3: A list of the papers presented at the AA Fest. A "*" indicates an invited paper.

\begin{tabular}{|c|c|}
\hline Celal Sukru Konor & $\begin{array}{l}\text { Simulations of Extratropical Cyclones Using the Generalized Vertical } \\
\text { Coordinate }\end{array}$ \\
\hline Jui-Lin Frank Li & $\begin{array}{l}\text { The Improvement of Planetary Boundary Layer Moist Processes in the UCLA } \\
\text { AGCM }\end{array}$ \\
\hline Chichung Lin & Development of an Empirical Cumulus Parameterization \\
\hline Rong Lu & Global Chemistry Simulations with the Coupled UCLA AGCM/ACTM \\
\hline $\begin{array}{l}\text { Victor Magaña and } \\
\text { Arturo Quintanar }\end{array}$ & Regional Climate Modeling over Mexico \\
\hline Steve L. Marcus & Extratropical Oscillations in the UCLA GCM: Pacemaker for the Tropics \\
\hline Shrinivas Moorthi & RAS and the new climate model at EMC \\
\hline Atusi Numaguti & A Lagrangian View of Water Cycle in the Atmosphere and Land \\
\hline $\begin{array}{l}\text { Arturo Quintanar and } \\
\text { Tercio Ambrizzi: }\end{array}$ & Low latitude forcing of Stationary waves in the Southern Hemisphere \\
\hline Xiaoqing Wu & Tropical Oceanic Cloud Systems \\
\hline Kuan-Man Xu & Roles of Cumulus Convection in the Easterly Waves \\
\hline Jin-Yi Yu & Impact of Stratus Clouds on Tropical Climate \\
\hline Ning Zeng & The First Quasi-Equilibrium Tropical Circulation Model \\
\hline \multicolumn{2}{|r|}{ End of Poster Session list } \\
\hline $\begin{array}{l}\text { Chin-Hoh Moeng and } \\
\text { Bjorn Stevens* }\end{array}$ & On the Representation of PBL Turbulence and Clouds in GCMs \\
\hline Michael Ghil* & Solving problems with $\mathrm{GCMs}$ \\
\hline Akimasa Sumi* & Climate Simulations \\
\hline Max Suarez* & Land Processes \\
\hline Steve Krueger* & Cloud-Resolving Modeling \\
\hline \multicolumn{2}{|r|}{ Session 3: Future Directions } \\
\hline David Neelin* & Convective Quasi-Equilibrium and the Tropical Circulation \\
\hline Donald Johnson* & Entropy, the Lorenz Energy Cycle and Climate \\
\hline David Randall* & Turbulence and Clouds \\
\hline C. Roberto Mechoso* & $\begin{array}{l}\text { An Atmosphere-Ocean GCM's Pilgrimage from Climate-Catastrophe to } \\
\text { Realistic Simulation/Prediction of ENSO }\end{array}$ \\
\hline Akio Arakawa* & Future Development of General Circulation Models \\
\hline
\end{tabular}


A banquet was held on the first evening of the Symposium. Michio Yanai provided an after-dinner talk illustrated with numerous slides. Robert Haney, Wayne Schubert, Syukuro Manabe, and Roberto Mechoso recalled their interactions with Akio Arakawa over the years, and offered interesting and sometimes amusing anecdotes. In addition, Master of Ceremonies Roger Wakimoto read congratulatory letters to Akio Arakawa from Kenneth Bergman, Lawrence Gates, Roger Newson, Ari Patrinos, George Philander, Robert Sadourny, Scott Sandgathe, and Joseph Smagorinsky. All in all, the Banquet speakers provided interesting insights into the history of atmospheric general circulation modeling research at UCLA and elsewhere, as well as a better understanding of Akio Arakawa's career and that of his students and colleagues.

In due course, a book based on papers presented at the Symposium will be published by Academic Press.

\section{Acknowledgements}

The Symposium was made possible through generous support from the National Science Foundation (ATM-9724980), the National Aeronautics and Space Administration (NAG 5-713, the Office of Naval Research (N00014-97-1-0983, the Department of Energy (013704), the Center for Climate System Research at the University of Tokyo, and the World Climate Research Program (12.547/S/FCD/V.8268, as well as the College of Natural Sciences at UCLA. Excellent administrative support was provided by the Department of Atmospheric Sciences and the Institute of Geophysics and Planetary Physics, both of UCLA.

\section{References}

Arakawa, A., 1966: Computational design for long-term numerical integration of the equations of fluid motion: Two-dimensional incompressible flow. Part I. J. Comp. Phys., 1, 119-143.

Arakawa, A., and W. H. Schubert, 1974: The interaction of a cumulus cloud ensemble with the 
large-scale environment, Part I. J. Atmos. Sci., 31, 674-701.

Johnson, D., and A. Arakawa, 1996: On the scientific contributions and insight of Professor Yale Mintz. J. Climate, 9, 3211-3224.

Phillips, N. A., 1956: The general circulation of the atmosphere: A numerical experiment. Quart. J. Royal Meteor. Soc., 82, 123-164. 